\title{
Grossmann and the Ontological Status of Categories ${ }^{1}$
}

Paul Symington and Jorge J. E. Gracia

Categories have become a salient topic in contemporary metaphysics. ${ }^{2}$ Such an invigorization indicates realignment with a long tradition in the history of philosophy by Aristotle, medieval scholastics, Kant, Husserl, and Ryle. There is much to recommend an approach to metaphysics that includes categorial investigations, not the least of which is the intuitively plausible and perennial notion that things with which we are acquainted ought to be understood as having commonalities among them. Metaphysics has been conceived as a discipline that, among other things, seeks to investigate common features of reality, thought, or language. It seeks to establish such features tout court in such a way that any entity whatsoever will either have a general feature in common with other entities or will itself be the category through which these entities are understood in common.

In addition, it is an oft-believed metaphysical view that some such features are presupposed by any correct understanding of the less general features under which entities are investigated or known. ${ }^{3}$ For example, although biologists mapping the human genome consider their subject matter in relation to an organism, they presuppose that their subject of investigation is individual. But individuality is a feature common to entities that is not considered by biologists. In this context, an aim of metaphysics would be to determine whether "individuality" is a general feature of entities, or, if it is not, how it can be accounted for by other more general features.

\footnotetext{
${ }^{1}$ This paper was published as the following: Paul Symington \& Jorge J. E. Gracia, "Grossmann and the Ontological Status of Categories," in Studies in the Ontology of Reinhardt Grossmann, ed. Javier Cumpa (New Brunswick: Ontos Verlag, 2010).

${ }^{2}$ Examples of works in the last twenty years in metaphysics that discusse categories are Jorge J. E. Gracia, Metaphysics and its Task: The Search for the Categorial Foundation of Knowledge (Albany: State University of New York Press, 1999); E. J. Lowe, The Four-Category Ontology: A Metaphysical Foundation for Natural Science (New York: Oxford University Press, 2006); Joshua Hoffman \& Gary Rosenkrantz, Substance among other Categories (Cambridge: Cambridge University Press, 1994); Amie Thomasson, Fiction and Metaphysics, (Cambridge: Cambridge University Press, 1999); Jan Westerhoff, Ontological Categories: Their Nature and Significance (Oxford: Clarendon Press, 2005); Roderick Chisholm, A Realistic Theory of Categories (Cambridge: Cambridge University Press, 1996); Ingvar Johansson, Ontological Investigations (New York: Routledge, 1989); Erwin Tegtmeier, Grundzüge einer kategorialen Ontologie: Dinge, Eigenschaften, Beziehungen, Sachverhal (Freiburg: Alber, 1992)

${ }^{3}$ W. H. Walsh, in his article, “Categories, ” Kant Studien 45 (1953-54), 274-85, defines categories as those concepts that are the ultimate non-empirical presuppositions of our empirical concepts. Categorial concepts are the criterion that establish some statements as being nonsense. His view is consistent with the general view of metaphysics expressed by R. G. Collingwood in his, An Essay on Metaphysics (New York: Oxford University Press, 2002), except Walsh identifies categories themselves as these absolute presuppositions.
} 
Many interesting questions may be raised either about categories as such or about specific categories. ${ }^{4}$ One could ask questions about the extension of categories: Are there any categories? and, what things are categories? Or, one could inquire regarding the intension of 'category': what exactly is a category? and how is category to be defined? A third line of inquiry could involve categories and causation: what causes categories? and how do categories arise? A fourth group of questions could be construed as broadly epistemological, such as: How can one come to know a given category, or the categories there are? and can categories be definitively established and grounded? A fifth set involves the relationship among categories and between categories and their members: What relationship do categories have among themselves, and what is the relationship between a category and the items that fall under it? Furthermore, one may ask about the relationship between categories and various kinds of investigations, such as, for example, the discipline, if any, that studies categories qua categories? Or one may raise questions concerning whether particular disciplines, such as the philosophy of mind, study categories. The question that is relevant to our present investigation, however, concerns the ontological status of categories.

\section{Ontological status}

The question concerned with the ontological status of categories can itself be subdivided into several others including the following: Are categories extra-mental entities such as attributes, qualities, relations, structures, sets, classes, or forms? Are they intra-mental entities, such as phenomena, mental acts, mental contents, or mental structures? Or, are they linguistic entities, such as meanings, words, types, tokens, predicates, or syntactical places? Common answers to these questions in the history of philosophy fall into at least four groups: (1) categories are linguistic entities, such as the words 'quantity' and 'substance,' by which we signify things; (2) categories are mental acts-or conceptssuch as the concept of "quality" or the concept "relation," with which we think about things; (3) categories are extra-mental features or properties of things such as being a quality, an attribute, or a relation; and (4) a last, inclusive, view that integrates the three previously mentioned positions by holding that categories are words, concepts, and properties but in different ways. ${ }^{5}$

One may be tempted to infer that the four views noted follow directly from the position one adopts with respect to realism, conceptualism, or nominalism regarding noncategorial entities. For example, it seems plausible to assume that if one believes that we know extra-mental entities as they are in themselves (to whatever degree), then it follows that one ought also to be committed to the extra-mental reality of categories. But this is not necessarily the case. It is logically possible for one to be a realist about entities and a conceptualist or nominalist about categories, as in the case where the essences of things are held to exist in the world but our broad groupings of these are regarded as

\footnotetext{
${ }^{4}$ Many of these questions have been identified by Gracia and Newton in "Medieval Theories of Categories," The Stanford Encyclopedia of Philosophy, Edward N. Zalta (ed.), URL = $<$ http://plato.stanford.edu/entries/medieval-categories/>.

${ }^{5}$ See Gracia \& Newton, "Medieval Theories of Categories."
} 
conceptual. ${ }^{6}$ And it is possible to hold a conceptualism about things and a realism about categories. Indeed, why could not one maintain that things in reality are not determined to be what they are through our concepts of them, while holding that the mental categories that we use to represent basic features of these things accurately reflect their reality? ${ }^{7}$ In short, the ontological status of categories cannot be derived from one's adoption of realism, conceptualism, or nominalism, and is complicated by the comprehensive character categories. ${ }^{8}$

The task of this chapter is to investigate and assess Grossmann's view of the ontological status of categories. It has two dimensions. Because Grossmann does not offer a full discussion of the ontology of categories, we first need to present an interpretation of his view. Our point of departure is Grossmann's claim that a category is a fundamental property of being (which implies that he holds view 3 above). Our second task is to assess the adequacy of his view. We do this by raising some problems with Grossmann's account, offering as an alternative view a version of 4 above, and defending it against what we construe as Grossmann's possible counter-arguments. We argue that the best way to view categories themselves is as ontologically neutral insofar as this opens the way for particular categories to be linguistic entities, mental acts, or properties of extra-mental things. This requires, in turn, a qualified defense of two views rejected by Grossmann — common natures and modes of being.

\section{Grossmann's View}

\section{A. Categories}

Grossmann explicitly recognizes the importance of categorial theory for the task and direction of metaphysics. In his main text devoted to categories, The Categorial Structure of the World, he identifies his ontological project as trying "to bring Aristotle's

\footnotetext{
${ }^{6}$ One could interpret William of Ockham in this way insofar as he held that there are ten categories but that there are not ten distinct classes of extra-mental entities. Of course, the issue is complicated in Ockham. On one hand, entities are really classified as being either substances and qualities, despite the fact that only individuals exist, with nothing shared between them. On the other hand, there are ten categories but the categories other than substance and quality do not refer to entities in the same way as substance and quality do. See Summa Logica I, 41.114-17, Opera Philosophica et Theologica, vol. 1, ed. Philotheus Boehner, Gedeon Gal, and Stephen Brown (St. Bonaventure: Franciscan Institute, 1974). For discussions on Ockham and categories: Gracia \& Newton, "Medieval Theories of Categories"; Giorgio Pini, "Reading Aristotle's Categories as an Introduction to Logic: Later Medieval Discussions about its Place in the Aristotelian corpus," in Lloyd A. Newton (ed.), Medieval Commentaries on Aristotle's Categories (Boston: Brill, 2007); William McMahon, "Reflections on Some Thirteenth- and FourteenthCentury Views of the Categories" in Michael Gorman and Jonathan J. Sanford (eds.), Categories:

Historical and Systematic Essays (Washington, D.C.: The Catholic University of America Press, 2004), pp. 45-57.

${ }^{7}$ Quine's ontological commitments seem to be this way. On one hand, in "Two Dogmas of Empiricism," in From a Logical Point of View (Cambridge: Harvard University Press, 1980), p. 44, he holds that our understanding of the world is dependent on one's own web of belief, and that this web is fluid. On the other hand, in "On What There Is," p. 15, he speaks of being itself in categorial terms in his famous dictum, "to be is to be the value of a bound variable."

${ }^{8}$ The question about the inclusiveness of categories is raised both by E. J. Lowe in Four-Category Ontology, pp. 40-44, and Jorge J. E. Gracia, Metaphysics and its Task, pp. 177-218
} 
Categories up-to-date. ${ }^{9}$ By this, he does not mean to adopt Aristotle's view, but rather to stress the importance that categories have for ontology, while taking "stock of ... ontological innovations of the last hundred years or so."10 True to his promise, he not only argues for a specific list of categories (such as individuals, properties, relations, and classes) with great force and awareness of the tradition of metaphysics, but also explicitly raises the intensional question about categories. In order to present Grossmann's view regarding what kind of entities categories are, we turn first to chapter 1, "The Task of Ontology," which explicitly addresses the nature of categories and their role in accomplishing this task.

Grossmann begins by identifying the distinctive nature of metaphysics with a two-fold task: (i) to establish the categories of the world, and (ii) to establish the laws that govern categories. ${ }^{11}$ He proceeds by giving some reasons for stressing the importance of categories in metaphysics. First, one is doing metaphysics when one makes a fundamental distinction between entities; e.g., the judgment that an individual object is not the same kind of entity as the properties that it possesses. Second, metaphysics is distinguished from natural science precisely through such a pursuit. Scientific investigations outside metaphysics involve a narrower conception of reality. For example, natural sciences presuppose the existence of individual physical things, whereas metaphysics countenances the possible existence of other entities, such as abstract entities, and seeks to categorize across the full range of existence, or, in other words, all facts that constitute the world. ${ }^{12}$

Regarding task (i), the metaphysician holds that each given entity is assigned to one and only one category. Thus, if an entity does not fit (i.e., is subsumed) into any previously established category, then a distinct category must be acknowledged as that under which this entity falls. ${ }^{13}$ Conversely, if entity $x$ and entity $y$ are thought to correspond to distinct categories, but $x$ and $y$ are not categorially distinct, then a metaphysician must identify them as belonging to the same category.

Grossmann avoids making many reductive moves that other ontologists have made. For example, he holds that categorization is not only required by the basic components of entities, but also by the complex entities which are made up of these basic components. He uses the example of the fact, "A is different from B" to illustrate this point. ${ }^{14}$ A philosopher who may hold to a purely analytical role for metaphysics may claim that there are only two possible categories corresponding to such a fact: the category Individual ( of which "A" and "B" are members), and the category Relation (of

\footnotetext{
${ }^{9}$ Reinhardt Grossmann, The Categorial Structure of the World (Bloomington: Indiana University Press, 1983), xv; henceforth, CSW.

${ }^{10} \mathrm{CSW}, \mathrm{xvi}$.

${ }^{11} \mathrm{CSW}, 4,5$.

12 On page 9, Grossmann holds that the world is one and the same as "everything there is." The world is a complicated fact. Thus, metaphysics establishes the categories of the world by investigating facts. This task is identical with the task of categorizing everything there is.

${ }^{13}$ Of course, another option would be to seek to reduce the entity itself into more basic principles that account for it. The question of reduction is one that Grossmann takes seriously. Here we assume that we are dealing with an irreducibly bona fide entity.

${ }^{14} \mathrm{CSW}, 7$.
} 
which "difference" is a member). However, Grossmann argues that there is a third possible category beyond the two mentioned: the category Fact, which only arises when complex entities are taken into account (of which " $\mathrm{A}$ is different from B" is a member). Also relevant for the understanding of his view is the claim that only existing things fall under categories, and that it is disciplines other than metaphysics that determine what exists or not.

Regarding task (ii), for Grossmann the metaphysician also establishes similarities and relations among categories, a procedure which in his view involves the discovery of categorial laws. Just as a physicist formulates laws to "describe the behavior of elementary particles ... [i] n ontology, similarly, the fundamental laws describe the behavior of categories." "So, ontology is interested not only in establishing a list of categories, but also in identifying the laws that exist among them by reflecting on their similarities and relations. This includes, for example, the description of the characteristic of changelessness that characterizes entities that fall under the distinct categories Property and Quantifier, as opposed to the category of Individual, which lacks this characteristic. Also, the ontologist seeks to explicate the special relationship between distinct categories. For example, one is not only to identify, say, the categories Individual and Property, but also the nexus of exemplification that holds between given entities in these two categories.

\section{B. Ontological status of categories}

Grossmann's pairing of metaphysics with categorial investigation leads to the question of what categories are. He characterizes a category as "a kind of entity." Indeed, not only are categories part of the furniture of the world, but so are the laws that hold among categories, such as the nexus of exemplification. This is enough to distinguish his view from several others by indicating that he is committed to the existence of categories: categories are indeed things in the world. However, he explicitly rejects the "old and hallowed tradition" of modes of being. ${ }^{16}$ According to him, this is the belief that there are different kinds of existence. He points out the distinction made by Bolzano, Russell and others, between subsistence (applying to, e.g., numbers, facts) and existence (applying to, e.g., material objects) as an example. ${ }^{17}$ Although not specifically mentioned by Grossmann, this seems to entail that he rejects the medieval distinction between the being proper to substances (esse) and the being proper to accidents (inesse), as well as another well-worn distinction between mental being (ens rationis) and real being (ens reale). For Grossmann, all these distinctions are vacuous, for existence is only of one kind, simpliciter, and categories fundamentally and completely divide it up.

Does Grossmann's rejection of modes of being render the question regarding the ontological status of categories meaningless? That is, if there are no modes of being of the sort described above, does it make sense to ask what kind of entity categories are? It does to the extent that for Grossmann identifying a thing's general characteristics (rather than its mode of being) reveals the kind of entity that it is. In this way, he believes that

\footnotetext{
${ }^{15} \mathrm{CSW}, 5$.

${ }^{16} \mathrm{CSW}, 9$.

${ }^{17}$ For example, see Bertrand Russell, Problems of Philosophy (Book Jungle, 2008), p. 84.
} 
differences in being are nothing other than fundamental categorial differences. This point will be more clear after our discussion of Grossmann's rejection of modes of being below. But for our present purposes, it is also clear that an investigation into the ontological status of categories is useful because, for Grossmann, one of the tasks of a metaphysician is to pick out similarities and differences between categories. Since categories are the basic determinations of existing things, we can ask whether there are also determinations that apply to all categories as categories, or whether there are attributes proper to categories as such that are not necessarily the same attributes as those that apply to entities that fall under them. An answer to this query would tell us something about the kind of entity that a category is.

To this end, Grossmann offers a characterization of the kind of entity that categories are that is very helpful for our purposes. One of the categories that he countenances and establishes is Property. ${ }^{18}$ Generally, Grossmann holds that properties are abstract entities - universals - that stand in a nexus of exemplification with individuals. And he argues that "being an existent" is not itself a category. He refers to categories as properties of entities: "categorial properties are properties among properties. Of course, they are much more general than 'ordinary properties.' But they belong to the same category as ordinary properties; they, just like ordinary properties, are exemplified by those things which have them." 19 Even though categories are both properties and entities, he also asserts that existence is not a property, insofar as it is "obvious that the variable entity is never attributed to anything" but is the ultimate substratum of properties. ${ }^{20}$ For Grossmann, the world is one-sorted in that the only "true and real vaiable" is entity, or existence. In this way, no entity, qua entity, is exemplified. However, properties are designated by the fact that they are able to be exemplified and so are categories. Categories are properties or similar to properties. ${ }^{21}$

\section{Properties}

${ }^{18} \mathrm{He}$ argues for their categorial status in CSW 102-54.

${ }^{19} \mathrm{CSW}, 404$.

${ }^{20} \mathrm{CSW}, 404$.

${ }^{21}$ One may reject our interpretation that a kind of entity is the same thing as an entity. For example, to say that a german shepherd is a kind of dog is not the same thing as saying that German Shepherd is a $d o g$ but rather it is saying that German Shepherd is a kind of dog. Likewise, it could be said that when Grossmann says that a category is a kind of entity he is not saying that categories are themselves entities but only kinds of entities. However, elsewhere he says that properties are abstract entities that are different entities from concrete entities, such as individuals (CSW 105ff). Categories are themselves properties. Therefore, they are entities. To put it another way, for Grossmann there are individual entities and there are entities that are properties, etc. The reason why individuals are individuals is because entities exemplify the property of being an individual and the reason why properties are properties is because entities exemplify the propery of being a propery. So too, the reason why individuals and properties are exemplified in the entities that they are is because individuals and properties exemplify the property of being a property or category. This is seen by the fact that individuals are individuals but Individual is also a property of those individuals. 
Since a category, for Grossmann, is a kind of property, we need to clarify his view of properties. First, he holds that properties are abstract entities, which means that they are neither in space nor time, and are changeless. ${ }^{22}$

Second, as abstract, properties are neither instances nor individuals; rather, they are universals that exist in the extra-mental world. A concept of a universal in someone's mind is not the universal, although the concept determines or refers to the universal entity that exists outside the mind. By 'universal,' Grossmann means that which can be shared or had by more than one entity. ${ }^{23}$ This is different from the view of properties as individual instances existing concretely in an object popular in the Middle Ages and maintained by Stout among others in the twentieth century. For Grossmann, one does not see a particular when one sees the color red that characterizes an object; one sees the universal "red." ${ }^{24}$ When one sees two red objects, one sees two objects and one universal shared by them.

Third, Grossmann claims that properties are related to individuals through the nexus of exemplification. This nexus characterizes the relationship between a given individual and any of its properties in such a way that the universal, non-spatial property is both not-identical and external to the individual, even though there is a mutual dependence between a property and the individual of which it is a property. This mutual dependence is understood as follows: on one hand, in order for a given property to exist there has to be at least one individual that exemplifies it. This view follows from the Principle of Acquaintance insofar as we cannot be acquainted with properties that are not exemplified by individuals. On the other hand, in order for an individual to exist, there has to be at least one property it exemplifies. This is articulated in what Grossmann's calls a fundamental law of ontology, which describes the necessary relationship between entitative status and properties: "an object exists if and only if it has a property.",25

In short, properties are abstract, universal entities. They are related to individuals through the nexus of exemplification in such a way that there cannot be a property without some existing thing that exemplifies it, nor can there be any existing thing that is not exemplified by a property.

\section{Properties and Realism}

Since a category is a special kind of property, what was said about the ontological status of properties above applies mutatis mutandis to categories. This leads us to Grossmann's important conclusion that all categories are real, extra-mental entities. And insofar as Grossmann analyzes all things under a common notion of existence, and there are no different modes of beings, but only one kind of being: existence simpliciter.

Early in the book, Grossmann supports realism by arguing against several claims that have traditionally been used by nominalists against it. These include the distinction between primary and secondary qualities, the relativity of sensation, the principle of

${ }^{22} \mathrm{CSW}, 105 \mathrm{ff}$.

${ }^{23} \mathrm{CSW}, 103$.

${ }^{24} \mathrm{CSW}, 115$. Grossmann defends at length his view that universals, although not in space or time, are nevertheless perceived by us.

${ }^{25} \mathrm{CSW}, 391$. 
reduction, and the view that perception is sensing plus inference. ${ }^{26}$ Another position that has often been thought to ultimately undermine realism is Descartes' "new way of ideas." Interestingly, instead of rejecting this last view, Grossmann embraces it and tries to show how it is consistent with realism. His acceptance of this doctrine is of particular interest in the discussion of his view of the ontological status of categories. ${ }^{27}$

According to Grossmann, Descartes' "new way of ideas" marks the modern break from the traditional Aristotelian way of establishing epistemological realism. A pervasive scholastic explanation for how extra-mental things are known in themselves is that there is a formal identity between an extra-mental nature and the concept through which things are understood. ${ }^{28}$ The foundation for this doctrine goes back to Aristotle's De anima in which he argues that there is a similarity or resemblance between an extra-mental thing and the thing thought about. ${ }^{29}$ Rejecting this doctrine, Descartes initiates a distinctive and pervasive philosophical tradition that holds among its tenets a non-identity and nonresemblance between material things and the ideas by which they are known. Standing in solidarity with Descartes on the view that "ideas...cannot be identical, not even in part, with its object ... [and that an idea] cannot resemble its object," Grossmann criticizes two arguments that propound that such an approach leads to skepticism. ${ }^{30}$

The first criticism argues that this view implies that only ideas, and not objects, can be known. This criticism assumes that the only way for an object to be known is for it to be represented by an idea, and the only way for an object to be represented by an idea is when the idea in some way resembles the object. Therefore, it follows that only ideas are represented by ideas.

Grossmann deflects this criticism by appealing to a special relation that exists between ideas and objects called the nexus of intentionality. ${ }^{31} \mathrm{He}$ characterizes this as the special relation that every mental act has to a particular object. ${ }^{32}$ The nexus of intentionality is not a relation of resemblance, identity, or, as he argues in the section on relations, a relation of representation. ${ }^{33}$ Rather, it is a unique relation between mental acts and the objects and/or properties that are intended by those acts. This unique relation is different from the relation of representation, which holds between our language and the world. In using language to communicate, we understand our words and sentences to represent the world we perceive. This relation is different from the nexus of intentionality in that the words we choose to represent features of the world is arbitrarily established by us, whereas some mental content that "intends a certain state of affairs is a matter that lies entirely outside of our choices .... If a certain act has certain content, then it cannot but

${ }^{26} \mathrm{CSW}, 19-33$.

${ }^{27}$ CSW, 27-29.

${ }^{28}$ Among the ranks of scholastics who held this position are Thomas Aquinas and John Duns Scotus.

${ }^{29}$ Aristotle, On the Soul, trans. by J. A. Smith, in The Complete Works of Aristotle, ed. by Jonathan Barnes (Princeton: Princeton University Press, 1984), Vol. 1, 16a3-8

${ }^{30} \mathrm{CSW}, 28$.

${ }^{31} \mathrm{CSW}, 28$.

${ }^{32}$ CSW, 189.

${ }^{33}$ Viz. CSW, 189-203. 
intend a certain object; for the content stands in the intentional nexus to that object."34 Thus, the nexus of intentionality is presupposed by the relation of representation in that, when speakers stipulate that a word represents an object, they already intend the object represented by it. Terms represent objects through an act of stipulation fixed through the nexus of intentionality.

The second, "more formidable" criticism against Descartes' way of ideas concludes that the Cartesian new way of ideas results in one not ever being able to know what object it represents*. ${ }^{35}$ This is because, in order to know that idea $X$ represents* object $x$, one needs to know $X$ and $x$ independently from each other. However, $x$ cannot be known except through $X$. Therefore, one cannot know whether $X$ does indeed represent* $x .{ }^{36}$ Let us call this the Comparison Problem. Whereas Grossmann accepts the claim that every object is known through an idea of it, he rejects the claim that to have idea $X$ is to know idea $X$. To have idea $X$ is to know object $x$; to know idea $X$ is to have another idea - for example, $Y$ - of it. By making this distinction, Grossmann argues that $x$ and $X$ can be compared to each other to see whether $X$ represents* $x$ or not. This can be done by comparing concept $X$ as representing* $x$, with concept $Y$, as representing* concept $X$. And so, Grossmann holds that even though $X$ does not resemble $x$, nevertheless, $X$ can be known to accurately represent* $x$ or not.

Applying this discussion to categories, we infer that Grossmann would hold that ideas (or mental contents) of categories do represent* categorial entities (which are a special kind of property) in such a way that there is no relation of resemblance, identity, nor representation, between them. Categorial terms represent categorial entities through convention and the ability for such terms to represent categorial entities is through the unique relation of intentionality. Furthermore, an idea $C$ of a category can be known to represent* a given categorial entity $c$ by comparing $C$ as representing* $c$ with an idea $P$ that represents* idea $C$.

\section{E. Rejection of Common Natures and Modes of Being}

Most important to our discussion is Grossmann's rejection of common natures, because we intend to defend the application of a strategy used in the doctrine of common natures to categories. Thus we turn to common natures now.

Beginning with the Muslim philosopher Avicenna (Ibn Sina), metaphysical realists have invoked so-called common natures to understand the relationship between universals and individuals. Grossmann needs to consider common natures, insofar as he rejects both conceptualism and nominalism in favor of a version of realism. For him, properties are not concepts, and the relationship between an individual and its properties is not the same as the relationship between a concept and that of which it is a concept.

\footnotetext{
${ }^{34} \mathrm{CSW}, 202$.

${ }^{35}$ In order to avoid confusion, we use the term 'representation*' for the term 'representation' and 'represents*' for the term 'represents' that Grossmann uses when he discusses this criticism. As mentioned above, Grossmann uses 'representation' to describe the relationship between terms and objects, which he distinguishes from the relation of intention. We take Grossmann's formulation of the problem presented in this paragraph to arise specifically in the context of the relation of ideas and objects and not between terms and the objects that they represent.

${ }^{36} \mathrm{CSW}, 29$.
} 
For example, the concept human is a concept of the property of being human (which Grossmann calls a species), and the property of being human is a property of many individual human beings, but the concept human is not a concept of individual human beings or a property of individual human beings. ${ }^{37}$ Grossmann's emphasis on properties leads to him to investigate the doctrine of properties conceived as common natures.

Grossmann distinguishes common natures from both concepts and individuals. ${ }^{38}$ Assume that there are two humanities: the humanity of Socrates (humanity ${ }^{+}$) and the humanity of Plato (humanity ${ }^{+}$). These two humanities are understood by two distinct concepts of humanity by John (humanity ${ }_{1}{ }_{1}$ ) and by Jane (humanity ${ }^{*}$ ). The superscript ' + ' indicates individual existence and the superscript ' $*$ ' indicates conceptual existence. The subscripts ' 1 ' and ' 2 ' indicate instances of either individual or universal existence. According to the theory of common natures, Grossmann says, "the concept human, as it exists in different minds, and the humanity which exists in different people, are supposed to be partially identical." 39 By 'partially identical', he means that on one hand, there is a common content in humanity ${ }^{+}{ }_{1}$, humanity ${ }^{+}$, humanity $^{*}{ }_{1}$, and humanity ${ }^{*}$; namely, humanity. This means that there is a commonality among John's concept and Jane's concept, between Socrates and Plato, between John's concept and Socrates, and so on. However, on the other hand, there is only partial identity among them because with respect to existence - indicated by '*' and ' + ' — each common nature has its own identity, which it shares with nothing else. So, although humanity ${ }_{1}{ }_{1}$ and humanity ${ }^{*}$ are both humanity existing as concepts, the existence of humanity as a concept in John's mind is not identical to the existence of humanity as a concept in Jane's mind. Thus, according to Grossmann, a "common nature binds certain concepts to certain objects, determining what objects these concepts have." 40

So, why does Grossmann reject common natures? According to Avicenna, common natures cannot in themselves be universal because this would prevent them from being associated with, or identified in, individual things. And Grossmann believes that he wrongly assumes that if what is predicated of a subject has a property, the subject also has that same property. For example, if human has the property of being universal, then it follows that Socrates must also have the property of being universal when human is predicated of him. ${ }^{41}$ For Grossmann, this view is a result of unduly conflating predication and class inclusion. Whereas in class inclusion a predicate of $S$ can also be predicated of $S$ (as when we predicate rational of Socrates, which is a mark of man), this is not necessarily the case with properties of properties of $S$. In the latter case, one need not impute the property of the property to the subject. For Grossmann, that humanity has the property of being universal does not entail that Socrates must also be universal. Rather, universals stand in a unique relation to individuals through the nexus of exemplification, so that, for example, the property humanity is in itself universal and stands in a nexus of exemplification with the individuals Socrates and Plato. From this Grossmann concludes

${ }^{37} \mathrm{CSW}, 123$.

${ }^{38} \mathrm{CSW}, 125$.

${ }^{39} \mathrm{CSW}, 125,126$.

${ }^{40} \mathrm{CSW}, 126$.

${ }^{41}$ CSW, 127, 128. 
that Avicenna's view that properties (or common natures) cannot be universal in themselves is unfounded and unnecessary.

An important feature of common natures, as traditionally understood, is that existence is not part of the formal identity of the common nature in itself. In contrast to Grossmann's own view that properties are universal and therefore not singular in themselves, he interprets the doctrine of common natures as asserting that common natures are (1) neither universal nor singular and (2) neither one (i.e., numerically) nor many. From this, he argues that this view implies that a common nature is not one entity and in reality "there is no such thing as a common nature." the doctrine, there has been a tendency to give some kind of being and unity to common natures (as John Duns Scotus did, for example), Grossmann suggests that the argument for common natures in its most fundamental form concludes that common natures are not entities in themselves.

In addition, Grossmann identifies another difficulty with the doctrine of common natures and their existence. Those who hold the doctrine claim that common natures exist individually in individuals (e.g., humanity in Socrates) and universally in the mind (e.g., humanity as a concept). But this, according to Grossmann, creates a difficulty that becomes evident when one considers them in terms of properties: a discrepancy between common natures understood in relation to individual material things and common natures understood in relation to immaterial concepts. Although humanity is understood as a property of Socrates, it is not understood as a property of the concept of humanity in Jane's mind in the same way, but in some other fashion. This is because, although it is true to say that "Socrates is human," it is not true to say "Jane's concept is human," even though one and the same common nature is understood to be expressed in both propositions. Given that the common nature humanity can be said to be the property of Socrates, while humanity cannot be said to be the property of humanity ${ }_{1}$, it follows that humanity ${ }_{1}$ cannot be partially identical to the humanity ${ }_{1}^{+}$that is Socrates. Rather than saying that a common nature is partially identical to a given concept, it is more appropriate to say that there is no identity relation whatsoever between a mental act and an object, but instead there is a relation of intentionality between them. Grossmann's final judgment on the doctrine is that "[w] hat convinces me more than anything else that the doctrine of common natures is false, is that the property of being human is in no sense of these terms a part of the concept, a constituent of the concept, or contained in the concept. If $X$ is a concept of $Y$, then $Y$ is as little a part of $X$ as Tom is a part of John if John is the father of Tom."

In the history of metaphysics, the Thomistic doctrine of common natures is accompanied by the doctrine of modes of being. This is so because the essence of a given common nature, as expressed by a definition, does not include a reference to its existence or the way the nature exists and, therefore, modes of being must be added to complete the picture. Because of this, Grossmann also argues against the doctrine of modes of being in The Categorial Structure of the World. Grossmann expresses the contrast between his

\footnotetext{
${ }^{42}$ CSW, 129.

${ }^{43} \mathrm{CSW}, 130$.
} 
regarding existence and the traditional metaphysical doctrine of modes of being in the following:

according to this school of thought, a distinction must be made between the genus of being, on the one hand, and various kinds [or modes] of being, certain species of being, or the other. I believe that this tradition is mistaken. There are no modes, no levels, no degrees of being. Being is not a genus. Rather, being is the unique and ultimate substance of the world. The category of being, to put it differently, consists of just one entity. ${ }^{44}$ To understand this position, first we must look at Gorssmann's analysis of modes of being and how the doctrine arises.

For Grossmann, modes of being have sprung from a mistaken notion of exemplification as conflated with the notion of existence. Understood correctly, exemplification is the unique relation that stands between an individual and its universal properties rather than the ways in which common natures are existentially realized. Much of the cause of the conflation is due to the fact that the relation of exemplification is often expressed by cognates of 'existence' in propositions. For example, in 'Socrates is a man," 'Socrates' and 'a man' are understood to stand in a relation of exemplification through the copula 'is.' The term 'is' or 'to be' has mistakenly been taken to express a generic notion of existence that requires specification or completion. "Socrates is" is understood to express exemplification of a generic notion of existence in the individual Socrates, even though such a predicate is incomplete and requires further specification. The specification of the generic notion of existence comes when predicate terms are joined with the copula. The copula and the predicate term are both predicated of the subject but with distinct intensions: the copula expresses existence, and the predicate term expresses a formal designation of the subject. Beyond this, a parallel condition is understood to hold between reality and the basic structure of predication: "Socrates is" is to "Socrates is a man" as "to be" is to "to be a man." In this way, "to be a man" is a mode of being ("to be").

However, whereas in "Socrates is a man" the individual Socrates is understood to be exemplified by the property "man," this does not imply that Socrates exists as some mode of existence. Similarly, in "Socrates is" the individual Socrates should not be understood as exemplifying existence, but rather it should be understood to mean that Socrates "has the unique feature of existence." 45

For Grossmann 'being' is univocal; it has only one meaning. Arguments that assert that entitative kinds imply kinds of existence are fallacious. Just because $x$ and $y$ are categorially different does not mean that $x$ and $y$ have different modes of being. Suppose that $x$ is a concrete entity (such as a cat) and $y$ is an abstract entity (such as the number 5). Instead of saying that $x$ is a cat implies that $x$ has a concrete mode of existence, or that $y$ is the number 5 implies that $y$ has an abstract mode of existence, we should realize that the first merely implies that $x$ is both an entity and concrete, and the second implies that $y$ is both an entity and abstract. The meaning of 'entity' for $x$ and $y$ is the same (or univocal).

\footnotetext{
${ }^{44} \mathrm{CSW}, 387$.

${ }^{45} \mathrm{CSW}, 388$.
} 
Grossmann contrasts his view with the position he rejects concerning the relation between common natures and modes of being as follows:

One and the same common nature, humanity, is claimed to exist mentally as a concept in the mind, and also materially in various people. But to exist mentally, we insist, is not to have a special form of existence. Rather, it is to exist as a mental entity. And similarly for material existence. The real mystery surrounding the notion of a Thomistic common nature, however, is revealed when we realize that it is one and the same entity which is said to exist in both forms. ${ }^{46}$

This text indicates that Grossmann recognizes that, in contrast with the doctrine of common natures, the doctrine of modes of being poses no "real mystery," suggesting that the doctrine of common natures goes hand-in-hand with that of modes of being. We are not surprised that Grossmann sees this compatibility since the doctrine of modes of being seems to be a sensible way to explain a partial identity between two non-identical things: between humanity ${ }^{+}$and humanity ${ }^{*}$ there is an identity of kind while simultaneously there is a non-identity in the way they exist. Still, Grossmann criticizes the doctrine of modes of being because "[n]one of the traditional arguments for modes of being which we have considered seems to be sound." ${ }^{, 47}$ In turn, a doctrine of common natures that implies modes of being is itself incorrect. Hence, Grossmann rejects common natures, developing an ontology devoid of appeals to modes of being.

As we saw earlier, for Grossmann a category is a special kind of property - the most general property under which an entity falls. And as with properties, where there is no relation of resemblance, similarity, or identity between our concepts and the properties that are represented* by them, there is no such relation between our concepts and the categories that are represented* by them. In this way, Grossmann rejects an analysis of categories as common natures and as involving basic modes of being. Existence, being, subsistence, and the like amount to the same thing, because existence as such does not admit of different kinds, even though things that exist fall under fundamentally different categories.

\section{Assessment of Grossmann's View}

\section{F. Problems in Grossmann's Account}

In The Categorial Structure of the World, Grossmann offers a remarkably integrated account of categories, but his view encounters difficulties to which we turn presently. Specific aspects of his position that we take issue with here include his view that categories are entities, that they are properties, his promulgation of Descartes "new way of ideas" and subsequent rejection of common natures, and his rejection of modes of being.

Grossmann's view that categories are universal properties faces significant difficulties. E. J. Lowe has pointed out in his recent book, The Four-Category Ontology, that the defining feature of universals is that they are exemplified by particulars.

\footnotetext{
${ }^{46} \mathrm{CSW}, 389$.

${ }^{47} \mathrm{CSW}, 392$.
} 
Roundness is a universal property, because it is exemplified by some individual object (such as a ball). Dogness is a universal property, because it is exemplified by some particular dog. But suppose, now, that we said that categories are universal properties. Then, more specifically, we should have to say that the category Property is also a universal property. But if so, it should be, or be capable of being, exemplified by some particulars. And what could those particulars be? Plainly, they could only be the various universal properties such as the property dogness. But the property dogness and the like are necessarily universal and so not particular. This means that the category universal property cannot be exemplified by particulars and hence cannot qualify as a universal. ${ }^{48}$ Thus, if universal property cannot be exemplified by universal properties, then a category itself cannot be a universal property.

Now, suppose that Grossmann does not rule out that universal properties can be exemplified by other universals, so that categories are second-order properties of first order properties. Does this strategy save this view? We think not.

Let $C$ be the property of being a category. Let $C_{E}$ be the extension of category; for example, Individual, Property, etc. Let $P$ be the entity that is the category Property itself. Let $P_{E}$ be the extension of the category Property; for example, redness, squareness, etc. Let $I$ be the entity that is the category Individual itself. Let $I_{E}$ be the extension of the category Individual; for example, Socrates, Plato, etc. $C_{E}$ is included in $P_{E}$, including both $P$ and $I$. However, $P_{E}$ has two orders: first-order and second order. Every first-order $P_{E}$ is a property that is exemplified by some individual(s). Every second-order $P_{E}$ is a property that is exemplified by some other property. Insofar as every $C_{E}$ is included in $P_{E}$, sometimes a $C_{E}$ as a $P_{E}$ is exemplified as first-order and sometimes as second-order. For example, $I$ as a $P_{E}$ is exemplified by individuals themselves - e.g., individual is exemplified by Socrates. However, $P$ as a $P_{E}$ is of the second order and exemplified by every first order $P_{E}$. Now this presents a problem. $I$ is a first-order $P_{E}$ and $P$ is a second order $P_{E}$. But $P$, although of a second order, is itself a $P_{\mathrm{E}}$ and so falls under $C_{E}$. At the same time, on Grossmann's view, $C$ is also a $P_{E}$. As a result, $P$ falls under $C_{E}$ while $C$, which is exemplified by every $C_{E}$ itself falls under that which falls under it. This is, of course, absurd because nothing can be more general than a category. ${ }^{49}$

Another problem with Grossmann's account of the relation between categorial concepts and categorial entities is evident through the consideration of the Cartesian new way of ideas. Let us consider the following scenario. There are two individual horses, Beauty and Beast, and two individual concepts (which in this scheme become ideas) of horses in John and Jane. According to Grossman, in this situation we have two individuals, Beauty and Beast, which exemplify the universal property horseness. At the

\footnotetext{
${ }^{48}$ Lowe, The Four-Category Ontology, 41. We have retained much of Lowe's language, but change the argument to fit Grossmann's specific position.

${ }^{49}$ This is a modified version of Lowe's argument in The Four-Category Ontology, 42. Beyond this, there is another problem similar to this one. Grossmann ofter refers to the nexus of exemplification, which he describes as a law that holds between entities in the category of individual and those in the category of property. A related question that surfaces here is how to account for such laws within his ontology of categories. It seems that he holds that at least some of these laws that hold among categories fall within the category of relation. This brings us back to a problem similar to holding that category is itself in the category of property.
} 
same time, there are two distinct mental acts in Jane and John each of which stands in a relation of intentionality to horseness. Now, an important question arises: is there a resemblance or partial identity between the distinct concepts (i.e., ideas) of horseness in Jane and John? Based on his accepted principles, Grossmann would have to give a negative answer. If he answered affirmatively, he would be rejecting a doctrine that he had argued for, namely, the "new way of ideas": that concepts in different minds are not related to anything beyond themselves through resemblance or similarity. This would seem to include difference not only between concepts (i.e., ideas) and objects, but also between concepts (i.e., ideas) in minds insofar as ideas in the mind are objects like anything else.

In order to avoid an affirmative answer, Grossmann could appeal either to (1) the doctrine of intentionality or (2) the nexus of exemplification. He could appeal to 1 by claiming that the mental acts of John and Jane, although distinct from each other, are related insofar as they both function through the nexus of intentionality to represent* one and the same universal property horseness. This may be fitting because Grossmann accounts for the way in which our concepts through mental acts accurately depict objects in terms of this unique relation. The doctrine holds that such mental acts intend some object, and human cognition is structured in such a way that it is intrinsically directed toward something other than itself. In this way, the notion of objectivity is grounded.

Also, Grossmann could appeal to 2 by claiming that the concept of horseness in Jane's mind and the concept of horseness in John's mind are related to each insofar as they both exemplify the universal property concept of horseness. ${ }^{50}$ This would allow him to hold that there is a relation between John's concept and Jane's conceps similar to the relation between Socrates and Plato considered as exemplifications of humanity, without saying that there is a resemblance between them. However, an appeal to 2 is an inadequate response not only because it strains the nexus of exemplification, which seems to be most appropriate in relating universals and individuals (and not universals and concepts ${ }^{51}$ ), but also either collapses into an affirmative response to the resemblance question or falls back on the nexus of intentionality (and so depends ultimately on 1). We may be able to understand how John's concept exemplifies the property of being a concept. However, it is not in virtue of the fact that John has a concept of horse that we understand his concept as resembling Jane's concept of horse. Rather, such an intuition about the resemblance between these two resides in the content of the concept itself and it is hard to see how exemplification can give us this content.

There seem to be two options here to explain this difficulty. The first is that John's concept of horseness exemplifies not only the property of being a concept, but also the "concept of horseness." Moreover, Jane's concept of exemplifies this same universal property. However, if this is the case, it is hard to see how the concept

${ }^{50}$ N.B., that it cannot be the case that John and Jane's ideas of horseness each exemplify the property of horseness, since, as Grossmann points out, "horseness" is not a property of the "concept of horseness," but only of individuals that are horses.

${ }_{51}$ It is difficult to intepret Grossmann understanding of concepts. It seems that they should fall under the category of individuals because he rejects property instances. But since he rejects property instances, and concepts were properties, it follows that our concepts are not our own! See CSW, 133ff. 
exemplified in John's concept does not resemble the horses that exists outside of his mind. Consider that what John thinks about when he thinks through his concept about horses is horses, and it is what he thinks about that serves him actually to identify existing horses. In this way, the option collapses into a position not easily distinguishable from the affirmative answer in which one holds that concepts resemble the extra-mentally existing objects they represent.

The second option is that what is exemplified by John's concept of horseness and Jane's concept of horseness does not resemble an extra-mental object such as a property because it is only a concept (and concepts themselves do not resemble such things). However, John's concept and Jane's concept are similar to each other in that they both exemplify concepts of horseness through which their mental acts intend the same objects. Given that the first option is not possible, in order to answer the problem of the relation between the concepts of horseness of Jane and John, Grossmann must appeal to 1 only.

However, the appeal to 1 is insufficient if Grossmann holds simultaneously to the notion that there is no relation of resemblance between concepts and their objects. That is, it can be argued that the doctrine of intentionality in fact supports the very idea that there is a relation of similarity or identity between John's concept and Jane's concept, and not only merely a relation between the concepts grounded in their representation* of the same object. Imagine a scenario where John has a concept of horseness which, through John's mental act, stands in a nexus of intentionality to the concept of horseness in Jane's mind. On Grossmann's view, there will be no identity or resemblance between John's concept and Jane's concept because such relations are precluded by the nexus of intentionality. However, it would be natural for John to conclude from this that his concept of horseness is in some way similar or identical to Jane's concept even though each has his or her own concept. It would be natural for him to say that Jane's concept is the same as his. This indicates that the relation between concepts that represent* the same properties or objects is that of similarity and not merely of intentionality.

Finally, Grossmann's non-resemblance, non-identity account of ideas does not avoid the charge of skepticism. Above, we presented the Comparison Problem which concludes that the Cartesian new way of ideas results in one not being able to know what a given idea represents*. Grossmann addresses this challenge by claiming that an object is indeed able to be compared to a concept that is thought to represent* it. The object $x$, represented* by concept $X$, is compared with another idea - for example, $Y$-which represents* the concept $X$. In this way, $X$ can be known to accurately represent* $x$ or not through $Y$. And this is the case even though $X$ does not resemble, nor is in any way identical with, $x$. However, Grossmann's response begs the question, for one cannot know if $X$ represents* $x$ by comparing $X$ with $Y$ if $X$ does not represent* $x$. Let us assume that $x$ is some object that is not a fox, that $X$ is the mental act associated with intending a fox, and that $Y$ is the mental act associated with intending the mental act of intending a fox. It does not seem in this context that a comparison of $x$ through $X$ and $Y$ will yield the insight into the fact that $X$ does not represent* a fox. The reason is that, on Grossmann's Cartesian view, only a comparison of mental contents is possible, even if mental content has an intentional structure. 
For these and other reasons, Grossmann's account of the ontological status of categories is inadequate. Many problems with it rest on Grossmann's rejection of common natures and modes of being. But these problems can be avoided if, adapting a part of the doctrine of common natures to categories, categories are considered in themselves to be indifferent or neutral to any particular way of being. That is, in hopes of offering a consistent ontological account of categories, one needs to prescind from committing to categories in themselves as exclusively determinate entities, such as extramental properties, concepts, or linguistic entities. ${ }^{52}$ We turn next to this view.

\section{G. Common Natures, Categories, and Ontological Neutrality}

Grossmann recognizes the potential value of common natures, but ultimately rejects them because he thinks that the doctrine is incoherent. ${ }^{53}$ We argue, however, that a part of the doctrine, if adapted to categories, serves to avoid some of the problems faced by Grossmann's own view of categories. The part of the doctrine that proves useful to us has to do with the neutral ontological status of common natures. By this, we mean that a common nature, qua common nature, cannot be said to have or not to have being. It is a mistake to think of common natures themselves as having entitative status because common natures are what things are, as expressed by their definitions, apart from any consideration of entitative status. Grossmann is right in his characterization of common natures to the extent that in themselves, "there is no such thing as a common nature," long as this is taken to mean that common natures are in themselves the sorts of things that cannot be said to exist or not exist. For common natures exist only as different entities and even across different modes of existing. They exist, for example, as individual material things and as universal concepts.

A common nature is the ground of formal identity among different entities. This formal identity, resemblance, or similarity ranges between two distinct individuals, an individual and a universal concept, or between two universal concepts. So, according to the doctrine of common natures, it is correct to say that there is a similarity between two individual horses, a concept of a horse and an individual horse, or between two concepts in two distinct persons. This doctrine involves modes of being insofar as to say that a horse is formally identical to the concept of a horse implies not only that the concept and the horse are not the same instance of horseness, but also that the concept and the horse exist in different ways.

Above we noted that giving categories a positive entitative status generates a problem because it requires that categories fall under a category. Indeed, an entitative status poses a dilemma. If categories are entities, then they require categorization; but if categories are not entities, how then is it, for example, that they can serve to ground the relation of similarity between a concept and an object? A way of avoiding this problem is to borrow from the doctrine of common natures the notion of their ontological neutrality

\footnotetext{
${ }^{52}$ For more on a neutral understanding of the ontological status of categories, see Gracia, Metaphysics and its Task, esp. chapter 9.

${ }^{53}$ For example, Grossmann says that the doctrine of common natures would be, if true, congenial to his approach. However, he holds that the doctrine is false. See CSW, 130.

${ }^{54} \mathrm{CSW}, 129$.
} 
and applying it to categories so as to remove from them any particular status of being when considered in themselves. This is why categories need not be categorized and at the same time serve to categorize. Perhaps Grossmann would recognize the value of this move since he argues that only beings fall under categories. ${ }^{55}$ However, assenting to this would not be without its costs to Grossmann's overall view given that he maintains that categories are properties and properties are beings.

A problem with this proposal frequently raised in the context of the doctrine of common natures is that common natures would not be in themselves beings. This has been interpreted as ontological cheating because it appears that this view simultaneously holds that there is no being in the common nature itself but that the common nature itself serves as a principle of unity among non-identical entities. This is seen as defying a fundamental law of ontology: you cannot have unity without being. In fact, this law seems to have compelled Scotus to give a kind of being to common natures (which we reject). And the same point can be applied, mutatis mutandis, to the doctrine of the ontological neutrality of categories.

Our way out of this difficulty in the context of categories is to say that categories in themselves have unity, but not the unity convertible with being. This unity is the kind that holds between two things that do not share any being in common, as happens with boundaries, holes, and privations (such as blindness), which are not entities. Take, for example, a large, flourishing maple tree. Certainly we would say that the tree is an entity and the physical boundary of the tree in space gives it a kind of proportion, orientation or limit to it; in fact, the tree seems to be almost dependent on the physical boundary in some way. However, the boundary cannot be said to be an entity like the color of the tree is. One can think of categories in a similar way. They serve as a kind of limit in such a way as to make something what it is.

To grant all categories a convertible unity with being would be to commit an ontological blunder, for each category has the unity proper to itself. A designation of being to a category considered in itself would contravene the unity that is properly convertible with the modes of existing of categories, whether mental, linguistic, and so on.

Grossmann argues against the neutrality of common natures by claiming that they depend on the incorrect conflation of predication and class inclusion, but that, when one sufficiently distinguishes between these two, the notion of similarity between a universal concept and an object vanishes. Aristotle, Grossmann points out, falsely assumes that the property of a subject is also the property of the concept of that subject. For example, since "human" is predicated of Socrates and "human" is included under "animal," it is assumed that "human" has the property of animal, which is a mistake. Although Socrates has the property of being a human, the concept "human" through which we think of the humanity of Socrates does not have the property of humanity. Thus, the claim that there is a relation of similarity or identity between a concept and the individual that is represented* by it is unfounded. He says that there is nothing in common between a concept and its object.

\footnotetext{
${ }^{55} \mathrm{CSW}, 9$.
} 
For our purposes, this argument is important because it can also apply to the neutrality of categories. So how do we account for this seeming lack of similarity between a concept and an object? We do so by holding to a broader notion of property than that described by Grossmann through the condition of predicability. Grossmann must admit that although common predication entails a common property, this does not mean that non-predicability in common means a non-similarity of property. If "human" can be predicated of both Socrates and Plato, we can infer similarity of property (or, in our view, category) between them. However, that one predicate can be predicated of one subject and not another does not mean that there is no similarity between the subjects. Although there is a similarity between horseness in an individual horse and horseness in the concept horseness, the non-predicability of "a horse" of "the concept horse" is accounted for by the fact they are expressions of the same common nature in different kinds of entities. This point is made by Peter Abelard: "being a man" (or the status of man) is not predicated of Socrates, whereas "man" is, and yet, there is a similarity expressed in common between man and being a man. ${ }^{56}$ In fact, there is a way of accounting for the similarity among individual objects and concepts given the condition of non-predicability among them. Namely, in a category is included only what it is to be $x$, whether $x$ is individual or conceptual. So, the relation of similarity between the individual horse and the concept instance of horse in John's mind is the fact that both are distinct expressions of one and the same "what it is to be the thing that it is."

But what about the problem of modes of being raised by Grossmann? As we mentioned above, Grossmann thinks that he can give a categorial account without committing to modes of being. However, the doctrine of modes of being is clearly implied by the neutrality view of the status of categories. Grossmann himself says that "the real mystery surrounding the notion of a Thomistic common nature, however, is revealed when we realize that it is one and the same entity which is said to exist in both forms." ${ }^{, 57}$ He seems to acknowledge that the problem of modes of being really consists in the problem of common natures, which have been addressed in our discussion of ontologically neutral categories. So, in making a case for the ontologically neutral status of categories we in turn make a case for modes of being.

\section{Conclusion}

In this chapter we have argued three points. First we have presented an interpretation of Grossmann's view, according to which categories are both entities and properties. Second, we have argued that this position encounters some major obstacles. And third, we have offered a way out of these obstacles by articulating a view of categories as ontologically neutral in themselves. This means that categories as such are neither properties nor entities, although particular categories can be.

\section{Franciscan University of Steubenville \& The University at Buffalo}

\footnotetext{
${ }^{56}$ Peter Abelard, Glosses on Porphyry in Paul V. Spade, Five Texst on the Medaieval Problem of Univerals (Hackett), 42.

${ }^{57}$ CSW, 389.
} 